\title{
Eye-head co-ordination in patients with Parkinsonism and cerebellar ataxia
}

\author{
N SHIMIZU, M NAITO,* A NDM YOSHIDA \\ From the Departments of Neurology and Ophthalmology, ${ }^{*}$ Jichi Medical School, Tochigi-ken, Japan
}

SUMMARY Eye-head co-ordination of patients with Parkinsonism and cerebellar ataxia was investigated and compared with that of normal subjects. In Parkinsonian patients eye-head co-ordination was of the same pattern as normals, with an accurate and stable gaze. Reaction times for both eyes and head, however, were prolonged. It was also noted that the contribution of head movements to gaze shift was abnormally large and that the gaze accuracy was decreased when the head was immobilised. In patients with cerebellar ataxia, gaze was dysmetric, often hypermetric, and was unstable during head movements. The contribution of head movements to gaze was also large. It is concluded that Parkinsonism and cerebellar diseases influence eye-head co-ordination differently.

In everyday life, eye movements are naturally associated with head movements. Both the head and eyes move to fixate the image of the target on the fovea, especially when a visual stimulus is presented far from the centre of vision. Bizzi and his collaborators ${ }^{1}$ showed that when a visual target is presented laterally to a monkey, the eye makes an initial saccade to fix the target on the fovea and then counter-rotates as the head begins turning toward the target. There is evidence that the initial saccade and the following head movement are centrally pre-programmed, while the counter-rotation of the eyes compensating for head turning is produced by the vestibulo-ocular reflex.

Clinical eye movement tests usually are performed with the head fixed. However, assessment of eye movements under the head-free condition may provide new information about naturally occurring eye movements as well as eye-head co-ordination processes. The purpose of this communication is to show how the eyes and head move in co-ordination in normal subjects as well as patients with Parkinsonism and cerebellar ataxia. It will be shown that the gaze is accurate and stable in Parkinsonian patients, while that in

Address for reprint requests: Dr N Shimizu, Department of Neurology, Jichi Medical School, Minamikawachi-machi, Kawachi-gun, Tochigi-ken, Japan, 329-04.

Accepted 18 February 1981 patients with cerebellar lesions is markedly dysmetric and unstable.

\section{Methods}

Subjects

Nine normal adults (four males and five females aged from 24 to 68 years, mean 44.9), nine patients with Parkinsonism (four males and five females aged from 28 to 74 years, mean 57.2), and nine patients with cerebellar ataxia (six males and three females aged from 24 to 55 years, mean $42 \cdot 0$ ) were examined. The neurological findings of the patients are summarised in tables 1 and 2 . In all subjects vision was normal and eye movements were of full range.

The diagnosis of the spinocerebellar degeneration was based on the criteria of the tentative classification of the spinocerebellar degenerations ${ }^{2}$ proposed by the Japan Research Committee on Spinocerebellar Degenerations: the predominantly cerebellar form including late cortical cerebellar atrophy and olivoponto-cerebellar atrophy, the cerebello-spinal form including Marie's ataxia, the predominantly spinal form, the degeneration of cerebellar nuclei and related systems including dentato-rubro-pallido-luysian atrophy ${ }^{3}$ and others.

Recording apparatus Head movements were recorded using a high speed, closed circuit television system (X-Y tracker, Hamamatsu TV Co) which was originally designed for measurement of eye movements. ${ }^{4}$ Both horizontal (X) and vertical (Y) movements of a small lamp placed on the forehead of the 
Table 1 Summary of clinical features of Parkinsonian patients

\begin{tabular}{|c|c|c|c|c|c|c|c|c|c|c|}
\hline \multirow[t]{2}{*}{ Patient } & \multirow[t]{2}{*}{ Sex } & \multirow[t]{2}{*}{ Age } & \multirow{2}{*}{$\begin{array}{l}\text { Duration } \\
\text { of } \\
\text { symptoms } \\
(y r)\end{array}$} & \multirow{2}{*}{$\begin{array}{l}\text { Stage } \\
\text { (Yahr's } \\
\text { classification) }\end{array}$} & \multirow[t]{2}{*}{ Rigidity } & \multirow[t]{2}{*}{ Tremor } & \multirow[t]{2}{*}{ Akinesia } & \multicolumn{3}{|c|}{ Eye movement } \\
\hline & & & & & & & & Pursuit & Saccade & $\begin{array}{l}\text { Gaze } \\
\text { nystagmus }\end{array}$ \\
\hline 1 & $\mathbf{M}$ & 47 & $3 \cdot 5$ & II & + & + & - & wnl & wnl & - \\
\hline 2 & $\mathbf{M}$ & 65 & 9 & III & + & + & + & Saccadic & Hypometric & - \\
\hline 3 & $\mathbf{F}$ & 38 & 16 & III & $+t$ & ++ & $+t$ & Saccadic & Hypometric & - \\
\hline 4 & $\mathbf{F}$ & 28 & 13 & III & + & + & + & Saccadic & wnl & - \\
\hline 6 & $\mathbf{F}$ & 73 & 7 & III & $+t$ & ++ & + & Saccadic & Hypometric & - \\
\hline 7 & $\mathbf{F}$ & 61 & 14 & III & ++ & $+t$ & ++ & Saccadic & Hypometric & - \\
\hline 8 & $\mathbf{M}$ & 58 & 4 & IV & ++ & ++ & $+t$ & Saccadic & Hypometric & - \\
\hline 9 & $\mathbf{M}$ & 71 & 6 & III & + & - & ++ & Saccadic & Hypometric & - \\
\hline
\end{tabular}

$\mathbf{M}=$ male $; \mathbf{F}=$ female $;-=$ absent $+=$ mild $:++=$ moderate; wnl = within normal limits.

Table 2 Summary of clinical features of patients with cerebellar ataxia

\begin{tabular}{|c|c|c|c|c|c|c|c|c|c|c|c|c|}
\hline \multirow[t]{2}{*}{ Patient } & \multirow[t]{2}{*}{$\operatorname{sex}$} & \multirow[t]{2}{*}{ Age } & \multirow{2}{*}{ Diagnosis } & \multirow{2}{*}{$\begin{array}{l}\text { Duration } \\
\text { of } \\
\text { symptoms } \\
(y r)\end{array}$} & \multirow{2}{*}{$\begin{array}{l}\text { Gait } \\
\text { ataxia }\end{array}$} & \multirow[t]{2}{*}{ Dysmetria } & \multirow[t]{2}{*}{ Decomposition } & \multirow{2}{*}{$\begin{array}{l}\text { Intention } \\
\text { tremor }\end{array}$} & \multirow{2}{*}{$\begin{array}{l}\text { Pyramidal } \\
\text { tract sign }\end{array}$} & \multicolumn{3}{|c|}{ Eye movement } \\
\hline & & & & & & & & & & Pursuit & Saccade & $\begin{array}{l}\text { Gaze } \\
\text { nystagmus }\end{array}$ \\
\hline $\begin{array}{l}1 \\
2 \\
3 \\
4 \\
5 \\
6 \\
7 \\
7 \\
8 \\
9\end{array}$ & $\begin{array}{l}\mathbf{M} \\
\mathbf{F} \\
\mathbf{M} \\
\mathbf{F} \\
\mathbf{M} \\
\mathbf{F} \\
\mathbf{M} \\
\mathbf{M} \\
\mathbf{M}\end{array}$ & $\begin{array}{l}23 \\
34 \\
43 \\
55 \\
52 \\
54 \\
32 \\
33 \\
50\end{array}$ & $\begin{array}{l}\text { DRPLA } \\
\text { Cerebellitis } \\
\text { Marie } \\
\text { OPCA } \\
\text { OPCA } \\
\text { OPCA } \\
\text { Marie } \\
\text { LCCA } \\
\text { SCD }\end{array}$ & $\begin{array}{l}20 \\
\text { is } 1 \text { month } \\
7 \\
10 \\
1 \\
2 \\
7 \\
2 \\
40\end{array}$ & $\begin{array}{l}++ \\
++ \\
+ \\
++ \\
+ \\
+ \\
+ \\
+ \\
+\end{array}$ & $\begin{array}{l}+ \\
+ \\
+ \\
+ \\
+ \\
+ \\
+ \\
+ \\
+\end{array}$ & $\begin{array}{l}+ \\
+ \\
+ \\
+ \\
+ \\
+ \\
+ \\
+ \\
+\end{array}$ & $\begin{array}{l}+ \\
+ \\
+ \\
+ \\
+ \\
+ \\
+ \\
+\end{array}$ & $\begin{array}{l}- \\
\overline{+} \\
+ \\
\bar{z} \\
\bar{t} \\
\bar{t}\end{array}$ & $\begin{array}{l}\text { Saccadic } \\
\text { Saccadic } \\
\text { Saccadic } \\
\text { Saccadic } \\
\text { Saccadic } \\
\text { Saccadic } \\
\text { Saccadic } \\
\text { Saccadic } \\
\text { Saccadic }\end{array}$ & $\begin{array}{l}\text { Dysmetric } \\
\text { Dysmetric } \\
\text { Dysmetric } \\
\text { Dysmetric } \\
\text { Dysmetric } \\
\text { Dysmetric } \\
\text { Dysmetric } \\
\text { Dysmetric } \\
\text { Dysmetric }\end{array}$ & $\begin{array}{l}\text { Present } \\
\text { Present } \\
\text { Present } \\
\text { Absent } \\
\text { Absent } \\
\text { Absent } \\
\text { Present } \\
\text { Present } \\
\text { Present }\end{array}$ \\
\hline
\end{tabular}

M=male; F = female; DRPLA = dentalo-rubro-pallido-luysian atropy; OPCA =olivo-ponto-cerebellar atropy; Marie=Marie's ataxia ; LCA = late cortical cerebellar atrophy; $\mathrm{SCD}=$ spinocerebellar degeneration, unclassified; $-=$ absent $;+=$ mild; $++=$ moderate.

subject were followed with a sampling rate of $15.75 \mathrm{kHz}$. The $\mathrm{X}-\mathrm{Y}$ tracker has advantages in monitoring natural head movements because it is not necessary to wear a helmet, which may slip on the head, or to wear a heavy apparatus, which may modify natural head movements. The relationship between the angular displacement of a spot of light and the corresponding output analog signals was linear over a range of \pm 35 degrees. The minimum angular displacement that could be resolved was about 1 degree. The electro-oculogram (EOG) was recorded with silver-silver chloride electrodes placed on both outer canthi and on the middle of the upper and lower margins of the right orbit. The EOG for horizontal eye movements was recorded with DC coupling, and its amplitude was linearly related to angular displacement of eyes over \pm 35 degrees range, with resolution of about 1 degree. The EOG for vertical eye movements was recorded with $\mathrm{AC}$ coupling for detecting eye blinks. The subjects were dark-adapted for at least 20 minutes prior to recording so that the baseline of the EOG was well stabilised. Gaze was computed electrically by summing EOG signals for horizontal eye position in the orbit and television tracker signals for horizontal head position in space.
Calibration The subjects sat in a chair 1.8 metres from a tangential screen. The head position signal was calibrated using a pen light with a cross-shaped slit attached to the vertex. The head was rotated so that the head-mounted light fell on a screen target of known angular eccentricity. The TV camera was adjusted to detect the lighted spot mounted on the forehead, and signals measured at known head angles were used for calibration. The axis of head rotation was established by positioning the subject under a plumb line. Head position and EOG calibrations were repeated frequently during the examination.

Experimental procedures A continuously illuminated round red target of 0.64 degrees in visual angle was projected on the screen and moved horizontally between points \pm 15 degrees from the centre at irregular intervals using a mirror galvanometer. Thus, the head position was eccentric prior to target movement, and gaze was shifted across the centre by 30 degrees alternately between the right and left. It took $8 \mathrm{~ms}$ for the target to make a shift. Subjects were instructed to follow the target as quickly as possible. In this situation, combined eye-head movements were in the "triggered mode", 5 in which the eyes make an initial 
saccadic movement, head movement toward the target follows, and the eyes make a compensatory movement during head movement.

\section{Results}

Eye-head co-ordination of normals

Normal human subjects scarcely moved their heads for $30^{\circ}$ gaze shifts, even when their heads were freely movable. Six of the nine normal subjects did not move their heads at all. The remaining three made small head movements (mean $3 \cdot 4^{\circ}$, table 3 ). When specially instructed to move the head, however, a relatively large head movement toward the target was initiated, resulting in counter-rotation of the eyes (fig 1A). Even in normals, the gaze was not always accurate at the end of an initial saccade. In 30 to 112 samples (mean 54) of eye-head co-ordination in each subject, the mean frequency of occurrence of dysmetric gaze at the end of an initial saccade in normals was $21 \cdot 3 \%$ (table 4 , fig $2 \mathrm{~A}$ ). The mean

Table 3 Reaction time, mean saccadic velocity and amplitude of head movement (mean $\pm S D$ )

\begin{tabular}{|c|c|c|c|c|}
\hline & \multicolumn{2}{|c|}{ (a) Reaction time } & \multirow{2}{*}{$\begin{array}{l}\text { (b) Mean velocity of } \\
\text { an initial saccade } \\
(\text { deg } / s)\end{array}$} & \multirow{2}{*}{$\begin{array}{l}\text { (c) Amplitude of } \\
\text { head movement } \\
(\text { deg })\end{array}$} \\
\hline & $\begin{array}{l}\text { Head } \\
(\mathrm{ms})\end{array}$ & $\begin{array}{l}\text { Eye } \\
(m s)\end{array}$ & & \\
\hline Normal $(n=9)$ & $227 \pm 26$ & $191 \pm 26$ & $220 \cdot 1 \pm 41 \cdot 4$ & $\begin{array}{l}0(n=6) \\
3 \cdot 4 \pm 1 \cdot 3(n=3)\end{array}$ \\
\hline $\begin{array}{l}\text { Parkinsonism }(n=9) \\
\text { Cerebellar ataxia }(n=9)\end{array}$ & $\begin{array}{l}330 \pm 110^{*} \\
320 \pm 70^{*}\end{array}$ & $\begin{array}{l}280 \pm 90^{*} \\
270 \pm 80^{*}\end{array}$ & $\begin{array}{l}194 \cdot 6 \pm 33 \cdot 6 \\
204 \cdot 7 \pm 44 \cdot 1\end{array}$ & $\begin{array}{l}11 \cdot 4 \pm 5 \cdot 0 \\
15 \cdot 6 \pm 6 \cdot 3\end{array}$ \\
\hline
\end{tabular}

Seven to 30 samples of eye-head co-ordination in each subject were measured.

(a) The reaction time of head of normals was obtained by asking to move the head.

(b) Mean velocity of an initial saccade: saccadic amplitude/saccadic duration.

(c) measured without instruction to move his head.

* Significantly different in comparison with normals $(p<0.02)$.

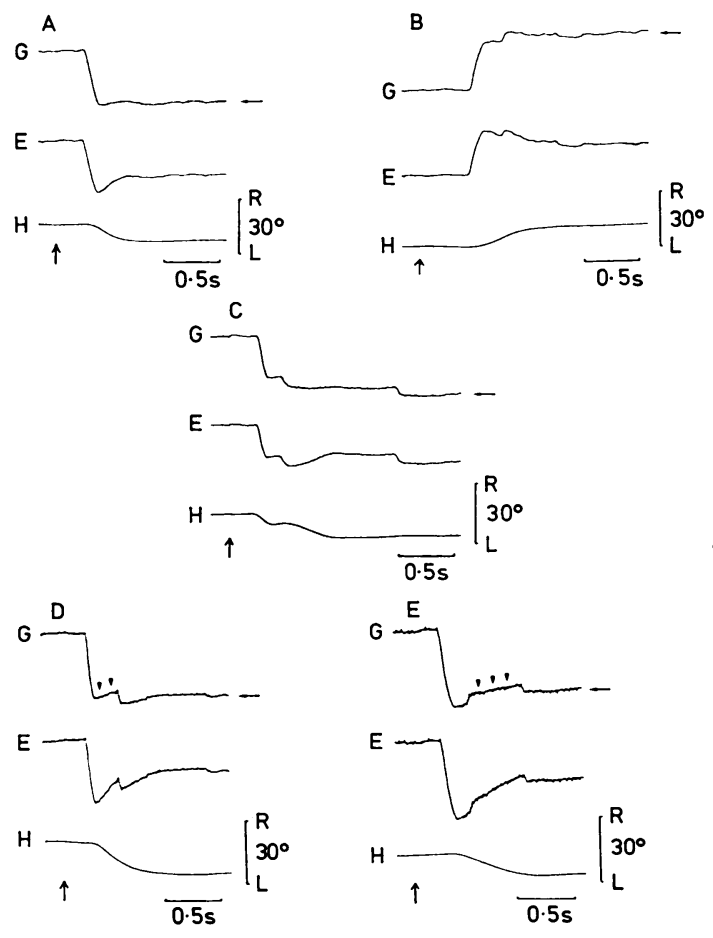

amplitude of dysmetria defined as the amplitude of overshoot or undershoot measured from the level of accurate gaze was $4 \cdot 3^{\circ}$ (table 4 , fig $2 B$ ). A drift of gaze during the intersaccadic period while the head was turning occurred in $5.5 \%$ of responses of normals (table 5, fig $2 \mathrm{C}$ ). The reaction times (latencies) of the head and eye movements and the mean velocity (saccadic amplitude/saccadic duration) of initial saccades are given in table 3 .

Fig 1 Eye-head co-ordination of a normal subject, a Parkinsonian patient and patients with cerebellar ataxia. (A): Eye-head co-ordination of a normal subject asked to move his head as well as his eyes. In this and following figures, $E=$ eye movement, $H=$ head movement and $G($ Gaze $)=$ the sum of $E$ and $H$. $A$ vertical arrow indicates the time of the target shift and a horizontal arrow indicates the level of an accurate gaze. (B): eye-head co-ordination of a patient with Parkinsonism. A hypometric initial gaze is corrected by a small saccade. $(C),(D)$ and $(E)$ : eye-head co-ordination of patients with cerebellar ataxia. The patients show hypometric $(C)$ and $(D)$ and hypermetric $(E)$ gaze. Arrow heads indicate the drift of gaze $(D)$ and $(E)$. 
Table 4 Frequency and amplitude of dysmetric gaze $(m e a n \pm S D)$

\begin{tabular}{|c|c|c|c|}
\hline & Normal & Parkinsonism & $\begin{array}{l}\text { Cerebellar } \\
\text { ataxia }\end{array}$ \\
\hline $\begin{array}{l}\text { frequency of } \\
\text { dysmetric gaze }(\%) \\
\text { hypermetria } \\
\text { hypometria }\end{array}$ & $\begin{array}{r}21 \cdot 3 \pm 12 \cdot 2 \\
2 \cdot 1 \pm 4 \cdot 0 \\
19 \cdot 2 \pm 14 \cdot 0\end{array}$ & $\begin{array}{r}37 \cdot 7 \pm 24 \cdot 8 \\
0 \cdot 5 \pm 1 \cdot 6 \\
37 \cdot 2 \pm 25 \cdot 0\end{array}$ & $\begin{array}{l}56 \cdot 2 \pm 17 \cdot 0 * \\
17 \cdot 0 \pm 20 \cdot 1 \dagger \\
39 \cdot 2 \pm 27 \cdot 9\end{array}$ \\
\hline $\begin{array}{l}\text { amplitude of } \\
\text { dymetria (degrees) }\end{array}$ & $4 \cdot 3 \pm 2 \cdot 0$ & $7 \cdot 7 \pm 4 \cdot 4$ & $9 \cdot 0 \pm 4 \cdot 1 \dagger$ \\
\hline
\end{tabular}

Thirteen to 112 samples (mean 54) of eye-head co-ordination in each subject were analysed. Gaze accuracy was evaluated at the end of an initial saccade. The amplitude of dysmetric gaze represents the amplitude of errors.

* =Significantly different in comparison with normals $(\mathrm{p}<0.001)$. $\dagger=$ Significantly different in comparison with normals $(p<0.01)$. hypometric and was followed by a few small corrective saccades (fig 1B). The mean amplitude of head movements is given in table 3. The occurrence of a dysmetric gaze at the end of an initial saccade, the mean amplitude of dysmetria and the occurrence of an unstable gaze during head movements did not differ from those of normals (tables 4 and 5 , figs $2 \mathrm{~A}, \mathrm{~B}$ and $\mathrm{C}$ ). The reaction times of head and eye movements were longer than those of normals $(\mathrm{p}<0 \cdot 02$, table 3$)$. However, the mean velocity of an initial saccade was not slower than that of normals (table 3 ).

In summary, Parkinsonian patients had essentially the same efficiency in eye-head co-
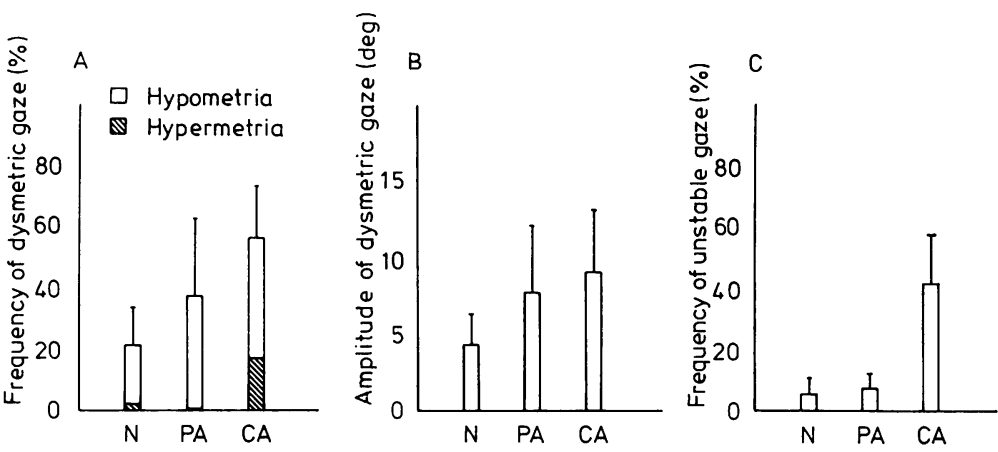

Fig 2 Frequency of occurrence and amplitude of dysmetric gaze, and frequency of occurrence of dysmetric gaze during head movement. (A): frequency of occurrence of dysmetric gaze at end of an initial saccade in eye-head co-ordination. In this and following figures, $N=$ normals, $P A=$ Parkinsonian patients and $C A=$ patients with cerebellar ataxia. Vertical lines represent one $S D$. (B): amplitude of dysmetric gaze, which is the amplitude of overshoot or undershoot measured from the level of an accurate gaze at the end of an initial saccade in eye-head co-ordination. (C): frequency of occurrence of unstable gaze during head movements.

Table 5 Frequency of unstable gaze during head movement (mean $\pm S D$ )

\begin{tabular}{lc}
\hline & Unstable gaze $(\%)$ \\
\hline Normal & $5 \cdot 5 \pm 4 \cdot 9$ \\
Parkinsonism & $7 \cdot 0 \pm 5 \cdot 1$ \\
Cerebellar ataxia & $41 \cdot 3 \pm 16 \cdot 2^{*}$
\end{tabular}

Twelve to 114 samples (mean 53.9) of eye-head co-ordination in each subject were analysed.

*=Significantly different in comparison with normals and patients with Parkinsonism $(\mathrm{p}<0.001)$.

\section{Eye-head co-ordination of patients with} Parkinsonism

In contrast to normals, the Parkinsonian patients always had an overt head movement during gaze shifts (table 3 ). The initial gaze shift was often ordination as normal subjects yielding an accurate and stable gaze, except for prolonged reaction times.

\section{Eye-head co-ordination of patients with cerebellar ataxia}

The patients with cerebellar ataxia also showed an overt head movement (table 3). The gaze usually was dysmetric, either hypometric or hypermetric at the end of an initial saccade (figs 1C, D and E). Dysmetric gaze was more frequent and the mean amplitude of dysmetria was larger than in normal subjects (table 4, figs $2 \mathrm{~A}$ and $\mathrm{B}$, $\mathrm{p}<0.001$ for frequency and $\mathrm{p}<0.01$ for amplitude). In particular, hypermetric gaze was more frequent in cerebellar patients $(p<0.01)$ than in 
normals (table 4, fig 2A). During head movement, unstable gaze, as characterised by drift as seen in figs $1 \mathrm{D}$ and $\mathrm{E}$, occurred frequently (table 5, fig 2C).

The gain of the vestibulo-ocular reflex in the dark was determined in two patients, and it was larger than that of normals (table 6). The reaction times of head and eye movements were longer than those of normals $(\mathrm{p}<0 \cdot 02)$. The mean velocity of an initial saccade was not different from that of normals (table 3 ).

Table 6 Gain of vestibulo-ocular reflex of patients with cerebellar ataxia

\begin{tabular}{lll}
\hline & $0.125 \mathrm{~Hz}$ & $0.25 \mathrm{~Hz}$ \\
\hline Patient 1 & 1.13 & 1.55 \\
Patient 9 & 0.81 & 0.71 \\
Normal values in our laboratory & $0.44 \pm 0.12$ & $0.45 \pm 0.17$ \\
(mean \pm SD) & & \\
\hline
\end{tabular}

Gain: peak amplitude of eye movement/peak amplitude of chair rotation (in the dark). Amplitude of sinusoidal chair rotation: $60^{\circ}$.

In summary, patients with cerebellar ataxia showed marked disturbances in gaze accuracy and stability during head movement. The frequency of occurrence and the amplitude of dysmetric gaze at the end of an initial saccade and of an unstable gaze were larger than in normal subjects.

Comparison of gaze between the head free and head fixed conditions

In four subjects of each group the gaze at the end of an initial saccade under the head free condition was compared with that when the head was restrained (figs $3 \mathrm{~A}$ and $\mathrm{B}$ ). In normal subjects and patients with cerebellar ataxia the frequency and amplitude of dysmetric gaze were not different in these two conditions. In the Parkinsonian patients, however, the frequency, but not the amplitude, of dysmetric gaze was increased under the head fixed condition $(p<0.01)$. Accurate gaze was attained more often at the end of an initial saccade when both the head and eyes were allowed to move in Parkinsonian patients.

\section{Discussion}

When a subject desires to redirect his gaze in a natural environment, he moves both the eyes and the head to image an object of interest on the fovea. Under our test condition of $30^{\circ}$ gaze shift, however, normal subjects usually moved the eyes quickly toward the target without any appreciable head movements. This is in agreement with
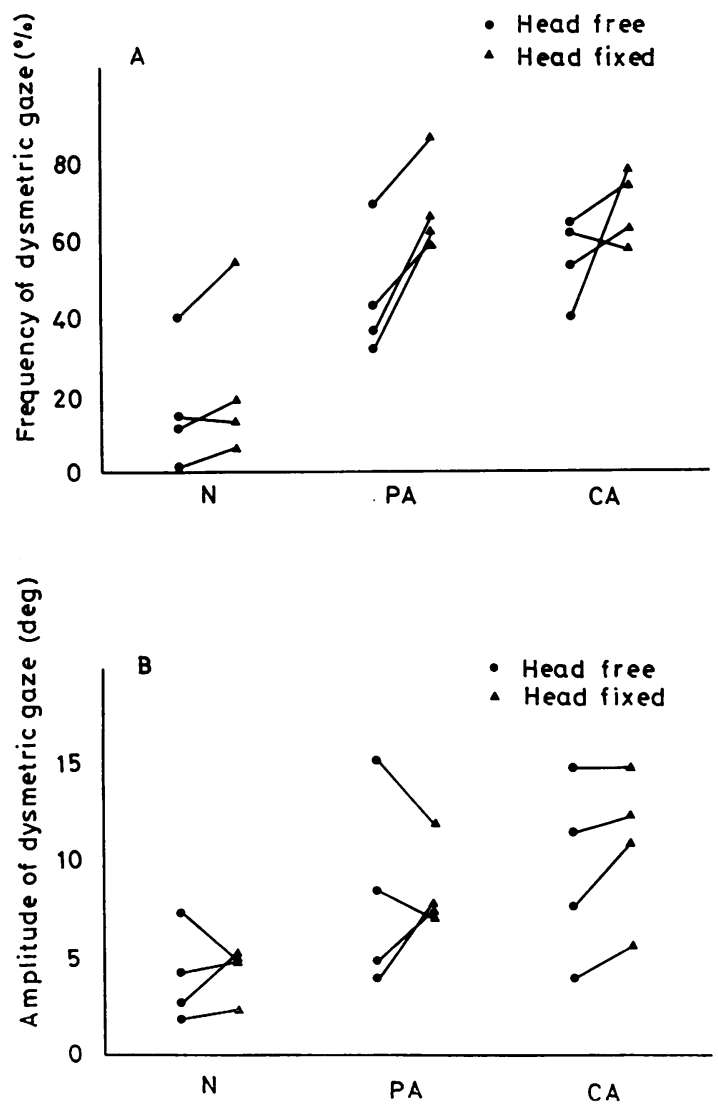

Fig 3 The comparison of the frequency of occurrence and the amplitude of dysmetria between the head free and head fixed conditions. $(A)$ : The frequency of occurrence of dysmetric gaze. (B): The amplitude of dysmetric gaze at the end of an initial saccade as defined in fig $2 B$.

previous observations in normal human subjects when they made gaze shifts of less than $40^{\circ} .^{\circ}$

In the evolution of mammals, eye movements became dominant over movements of the body axis and head. ${ }^{7}$ The saccade associated with head movements is thought to be more reflexive in nature and phylogenetically older than voluntary saccades without head movements. ${ }^{8}$ Normal children become able to make voluntary saccades without moving the head after the age of five years. ${ }^{9}$

In normal subjects, awareness of being examined presumably activates the phylogenetically newer mechanism to make $30^{\circ}$ gaze shifts without any discernible head movement. In contrast, patients with Parkinsonism and cerebellar 
ataxia always moved their heads as well as their eyes, and the contribution of head movements to the gaze shift was large. This could be explained if the phylogenetically newer mechanism is much more susceptible to the brain lesions than the older one, the latter thus becoming dominant in these patients. The gaze of Parkinsonian patients was very stable during head movements, perhaps due to an adequate vestibulo-ocular reflex. Since the gaze accuracy in Parkinsonism was decreased when the head was fixed, Parkinsonian patients seem to achieve accurate gaze by using the phylogenetically older mechanism instead of the newer one.

The saccadic velocity in Parkinsonism was not decreased in comparison with that of normals; other reported results are conflicting, perhaps owing partly to the method of measuring eye velocity and partly to the pathology of the patients. ${ }^{10^{-12}}$ The prolonged reaction times of head and eye movements are in agreement with previous reports ${ }^{12-14}$ and may be a part of the bradykinesia of Parkinsonism.

The characteristics of eye-head co-ordination in patients with cerebellar ataxia included dysmetric, particularly hypermetric gaze at the end of an initial saccade and unstable gaze during head turning. Saccadic dysmetria has been observed both in experimental animals and in patients with cerebellar lesions. ${ }^{15-20}$ Our results showed that gaze dysmetria also occurred in conjunction with the head movement.

The gaze of patients with cerebellar ataxia was often unstable during head movements. There might be three reasons for a drift of gaze during head turning: (1) the slow phase of gaze nystagmus, (2) inability to maintain the eyes laterally, and (3) inappropriate compensatory eye movements for head turning. For example, the drift of gaze after an initial saccade in fig 1D could be due to nystagmus. Counter-rotation of the eyes for head turning is influenced by vestibular, visual and neck afferents. But it was shown in monkeys that the vestibulo-ocular reflex is most responsible for gaze stability during head turning. ${ }^{21}$ In patients with cerebellar dysfunction, hyperactive caloric and rotational responses and an increased gain of the vestibulo-ocular reflex (peak eye velocity/peak head velocity) have been observed, 192223 and adaptive modification of the vestibulo-ocular reflex by the cerebellum has been demonstrated in experimental animals. ${ }^{24-26}$ In fact, the gain of the vestibulo-ocular reflex was increased in our patients, although only two patients were evaluated. The inappropriate vestibulo-ocular reflex seems to be partly responsible for the unstable gaze during the head movement in our patients.

An initial saccade and the following head movement of eye-head co-ordination are centrally preprogrammed and are completely adequate even when a visual target is turned off just prior to the eye movement. ${ }^{121}$ Disturbances of the predictive control of the ballistic gaze shift and adaptive gain control of the vestibulo-ocular reflex by the cerebellum may account for the dysmetric and unstable gaze observed in patients with cerebellar ataxia.

The authors express their thanks to Prof $\mathrm{K}$ Maekawa, Prof M Ito, and $\operatorname{Dr} M$ Anderson for their critical reading of the manuscript and improvement of the English.

The work was supported by Grants 212009 and 311410 from the Ministry of Education of Japan.

\section{References}

1 Bizzi E, Kalil RE, Tagliasco V. Eye-head coordination in monkeys. Evidence for centrally patterned organization. Science 1971; 173:452-4.

2 Kondo K. Genetic patterns of hereditary ataxias in Japan. With emphasis on cerebellar ataxias in adults. In: Japan Medical Research Foundation ed. Spinocerebellar Degenerations. Tokyo: University of Tokyo Press, 1980; 143-62.

3 Smith JK. Dentatorubropallidoluysian atrophy. In: Vinken PJ, Bruyn GW, eds. Handbook of Clinical Neurology. Amsterdam: North-Holland Publishing Company, 1975; 21:519-34.

4 Ishikawa S, Yamazaki A. A new instrument for recording of the eye movement. Jpn J Ophthalmol 1973; 17:244-8.

5 Bizzi E, Kalil RE, Morasso P. Two modes of active eye-head coordination in monkeys. Brain Res 1972; 40:45-8.

6 Bartz AE. Eye and head movements in peripheral vision: nature of compensatory eye movements. Science 1966; 152:1644-5.

7 Hassler R. Supranuclear structures regulating binocular eye and head movements. Bibl Ophthalmol 1972; 82:207-19.

8 Zee DS, Yee RD, Singer HS. Congenital ocular motor apraxia. Brain 1977; 100:581-99.

9 Kuromaru S, Okada Y, Hanada M, Uchida S, Oue $M$. Neurological soft signs in children. Psychiatria et Neurologia Paediatrica Japonica 1964; 4:69-77.

10 Highstein S, Cohen B, Mones R. Changes in saccadic eye movements of patients with Parkinson's disease before and after L-Dopa. Trans Am Neurol Assoc 1969; 94:277-9.

11 Melvill Jones G, DeJong JD. Dynamic characteristics of saccadic eye movements in Parkinson's disease. Exp Neurol 1971; 31:17-31. 
12 Shibasaki H, Tsuji S, Kuroiwa Y. Oculomotor abnormalities in Parkinson's disease. Arch Neurol 1979; 36:360-4.

13 DeJong JD, Melvill Jones G. Akinesia, hypokinesia, and bradykinesia in the oculomotor system of patients with Parkinson's disease. Exp Neurol 1971; 32:58-68.

14 Corin MS, Elizan TS, Bender MB. Oculomotor function in patients with Parkinson's disease. J Neurol Sci 1972; 15:251-65.

15 Aschoff JC, Cohen B. Changes in saccadic eye movements produced by cerebellar cortical lesions. Exp Neurol 1971; 32:123-33.

16 Komatsuzaki A, Mizutani J. Nystagmus and abnormal eye movement in the cerebellar disease. Advances in Neurological Sciences 1975; 19:649-61.

17 Ritchie L. Effects of cerebellar lesions on saccadic eye movements. J Neurophysiol 1976; 39:1246-56.

18 Selhorst JB, Stark L, Ochs AL, Hoyt WF. Disorders in cerebellar ocular motor control-I. Saccadic overshoot dysmetria. An oculographic, control system and clinico-anatomical analysis. Brain 1976; 99:497-508.

19 Zee DS, Yee RD, Cogan DG, Robinson DA, Engel WK. Ocular motor abnormalities in hereditary cerebellar ataxia. Brain 1976; 99:207-34.
20 Baloh RW, Honrubia V, Sills A. Eye-tracking and optokinetic nystagmus. Results of quantitative testing in patients with well-defined nervous system lesions. Ann Otol Rhinol Laryngol 1977; 86:108-14.

21 Dichgans J, Bizzi E, Morasso P, Tagliasco V. Mechanisms underlying recovery of eye-head coordination following bilateral labyrinthectomy in monkeys. Exp Brain Res 1973; 18:548-62.

22 Baloh RW, Konrad HR, Honrubia V. Vestibulo. ocular function in patients with cerebellar atrophy. Neurology (Minneap) 1975; 25:160-8.

23 Baloh RW, Jenkins HA, Honrubia V, Yee RD, Lau CGY. Visual-vestibular interaction and cerebellar atrophy. Neurology (Minneap) 1979; 29: 116-9.

24 Ito M, Shiida T, Yagi N, Yamamoto M. The cerebellar modification of rabbit's horizontal vestibulo-ocular reflex induced by sustained head rotation combined with visual stimulation. Proc Jpn Acad 1974; 50:85-9.

25 Miles FA, Fuller JH. Adaptive plasticity in the vestibulo-ocular responses of the rhesus monkey. Brain Res 1974; 80:512-6.

26 Robinson DA. Adaptive gain control of vestibuloocular reflex by the cerebellum. I Neurophysiol 1976; 39:954-69. 